\title{
Incorporation of Early Career Researchers (ECRs) within multidisciplinary research at academic institutions
}

\author{
A.J.Sobey, $\quad$ N.C. Townsend, C.D. Metcalf, K.D. Bruce, \\ F.M. Fazi \\ University of Southampton, University Road, Southampton. SO17 1BJ
}

April 8, 2013

\begin{abstract}
Multidisciplinary research is becoming an increasingly popular approach by many international, national and institutional organisations to address global grand challenges and provide innovative solutions. However, within an academic setting, Early Career Researchers are underutilized in this field. This underutilisation can come from many factors, arising from current performance metrics, fixed term contracts, lack of opportunities and institutional strategies. To address these issues and to aid the process of retaining talented ECRs, an initiative was launched to incorporate ECRs and to support the existing multidisciplinary strategies. This paper describes and shows some initial results of these new contribution$\mathrm{s}$ to inform other academic institutions developing policies that incorporate ECRs within their multidisciplinary networks. The initiative represents one approach to educate and provide guidance to ECRs on the benefits and issues associated with multidisciplinary research.

Multidisciplinary Research; Early Career Researchers; (ECRs) Academic Strategy; Research Funding;
\end{abstract}

\section{Nomenclature}

[Table 1 about here.]

\section{Introduction}

Universities and individual researchers aim to produce internationally distinctive research looking to improve social, economic or environmental conditions to solve the grand challenges of the current era. One method put forward, and supported by many research institutions, research councils and government, is the use of multi-, inter- or crossdisciplinary research to provide innovative solutions to these problems, for example (Cubism, The Human Genome Project, Magentic Resonance Imaging and manned space flight) amongst others. Choi and Pak (2006) found dictionary definitions for these terms: Multidisciplinary composes of or made up of several specialised branches of learning, for achieving a common aim; interdisciplinary is combining or involving two or more academic disciplines or fields of study and crossdisciplinary is involving two or more academic disciplines. This paper focuses on integrating researchers working across traditional borders and focuses on multidisciplinary but includes, within this definition, interdisciplinary or crossdisciplinary researchers who need support. While much of academia has concentrated on traditional areas of research or disciplines, or developing new areas through the amalgamation of traditional ones (e.g. bioengineering, marine archaeology, sports science), there is a growing trend towards multidisciplinary research; gathering experts from different disciplines together to solve problem(s) that share a common

*ajs502@soton.ac.uk 
link.

Multidisciplinary research, bridging conventional boundaries and linking research disciplines, can facilitate new scientific breakthroughs Hollingsworth and Hollingsworth (2000), address societal problems Lowe and Phillipson (2006) and foster innovation Gibbons et al. (1994). At a time when science is increasingly under pressure to become more relevant to society Nightingale and Scott (2007); Hessels (2010) multidisciplinary research challenging established beliefs or disciplines, developing new research avenues and creative ventures not only provides an unique contribution but contributes towards science's on-going progression Jacobs and Frickel (2009). However, to facilitate and sustain the multidisciplinary research agenda, researchers, especially Early Career Researchers (ECRs), defined here as anyone who considers themselves to be at an early stage in their career for example final year $\mathrm{PhD}$ students, post-doctoral researchers and early stage lecturers or equivalent levels in non-research posts, require encouragement and support to participate and develop multidisciplinary research projects. Although multidisciplinary research offers many opportunities there are also challenges to overcome such as discipline working styles and 'language' barriers which can be create numerous problems for ECRs as they are less experienced.

The barriers that must be overcome are particularly prevalent amongst ECRs. However, as discussed by Rhoten and Pfirman (2007) little is known about the characteristics of individual researchers that are likely to partake in multidisciplinary research. Rijnsoever and Hessels (2011) expand upon this point and show that it will be important for further research to determine what can be done to encourage more young researchers in engaging in interdisciplinary research. Furthermore Rijnsoever and Hessels (2011) agree that these rewards should not automatically be financial Bozeman and Corley (2004) have shown that the inclusion of early career researchers in projects does not ensure that they have collaboration opportunities or that these opportunities, if available, will enhance their abilities. It is therefore vital that to encourage ECRs into multidisciplinary research that new methods of encouragement are developed which allow collaboration and individual development.

This paper presents preliminary results of our recent advances at the University of Southampton to integrate ECRs into the current multidisciplinary research environment. This includes a new ECR committee and events to educate and incorporate ECRs into the current framework for multidisciplinary research at the University. This paper describes initial results of these new contributions in the hope of inspiring other academic institutions to incorporate ECRs more closely within their multidisciplinary networks.

\subsection{University of Southampton Strat- egy}

The University of Southampton's research strategy aims to generate world-leading and internationally distinctive research to address society's biggest and most pertinent problems, through innovative approaches bridging conventional boundaries and research disciplines; that is, through multidisciplinary research. This strategy Attard and Nelson (2010) is driven by the Research Council's agenda, where some 15 per cent of the Research Councils UK budget is devoted to 'global challenge'. In response to these 'multidisciplinary' funding opportunities, the University has developed University Strategic Research Groups or USRGs in order to facilitate and develop cross-faculty, multidisciplinary initiatives. The structure and role of the USRGs within the University management matrix is illustrated in table 1 whereby it encourages academics not to consider themselves part of one traditional silo,such as maths, but to consider also how this skill set can be applied to a multitude of timely problems, such as the digital economy.

\section{[Table 2 about here.]}

The USRG's, which will grow and develop and become extinct, where necessary, aim to provide 
official support for areas of interest among academics and researchers across the faculties. The academics and researchers at the University remain employed within the faculty structure, the top row of table 1, and the USRGs provide a structure to connect them and to solve problems not wholly suited to one discipline. The USRGs will respond and tailor their activities to meet the needs of the members while addressing key national and international priorities set out by the research councils. At the moment there are 12 USRGs and 2 Institutes.

The USRGs active members are largely senior academics while, for various reasons arising from current performance metrics, fixed term contracts, lack of opportunities and awareness, ECRs are under underrepresented and underutilised. To ensure the long term, continual success of the USRGs and for the long term sustainability of multidisciplinary research agendas, more ECRs need to be encouraged to participate and develop multidisciplinary research projects. By presenting and discussing the initiatives and results made at the University of Southampton to integrate ECRs into the current multidisciplinary research environment, our intention is to inspire other academic institutions to incorporate ECRs more closely within their multidisciplinary networks.

\section{$1.2 \quad$ Early Career Researchers (ECRs) Involvement}

While many academics and institutions agree that incorporation of ECRs into multidisciplinary research is an important activity, it can be hard to incorporate them in a manner which works and is sustainable Reeves et al. (2012). As a result ECRs are often underrepresented to the detriment of the host institution's research and strategic agendas. The reasons for this are often attributed to factors including:

- fixed or short term contacts;

- inflexible performance metrics;

- difficulties writing new research bids;
- perceived lack of opportunities by ECRs;

- lack of specific incorporation within strategy.

This can be further compounded when multidisciplinary research is performed by senior academics employing interdisciplinary researchers or postgraduates, without the researchers developing multidisciplinary research skills, contacts and networks. That is, not developing the next generation of multidisciplinary academic leaders.

To explore and identify the full range of issues surrounding ECRs involvement within multidisciplinary research, and attempt to address them, a committee and conference were organised. This paper describes the committee formation and structure and the conference, the Southampton Multidisciplinary Research Forum (SMuRF). These initiatives are now becoming formally integrated within the USRGs/University strategy to help facilitate ECRs within the multidisciplinary research at University of Southampton.

\section{Methodology}

In response to these challenges, the Southampton Multidisciplinary Research Forum (SMuRF) was developed led by an ECR focused committee aiming to foster collaborative relationships and novel research avenues in line with the University's research strategy, and that of current 'knowledgeable society'.

\subsection{Committee}

The purpose of the committee was to integrate ECRs within the current multidisciplinary environment for mutual benefit (individual researchers and the University) and provide an on-going structure to support and communicate ECR issues. The aim of the committee is to provide ECRs with the opportunities to develop multidisciplinary research interests, projects and careers. The roles of the committee include: USRG support, ECR support, ECR utilization and ECR committee sustainability. 


\section{USRG Support}

The ECR committee forms a link between the USRGs and the ECR community allowing information to be passed to the ECRs about what is required from them and how to excel in this new multidisciplinary environment; examples of this are how to prepare CVs for multidisciplinary promotions, joint faculty employment and the Research Excellence Framework (REF), the system for assessing the quality of research in UK higher education institutions to be completed in 2014. The ECR committee also allows information to be passed upwards to allow the USRGs to determine what information ECRs are lacking and what events may help in recruiting. The ECR committee members have been selected so that their primary research interests span a range of disciplines and there is one member of the committee on each USRG. As a result ECR committee members are now incorporated into the USRGs to facilitate greater ECR interaction and allow continued development of interests in multidisciplinary research.

\section{ECR Support}

The ECR committee itself will provide an environment to determine what problems arise for ECRs and their involvement in multidisciplinary research, and to collectively formulate potential solutions. It will also reinforce relationships between ECRs from a range of disciplines that will grow alongside their research interests and careers. It is anticipated that relationships formed whilst sharing common issues and solving common problems will have a greater longevity. An example of issues raised have included ECRs attainment of author credit from multidisciplinary publications, particularly in light of the discipline-centered review panels for the Research Excellence Framework (REF) whereby each UK academic is aiming to be selected to enter their research before a panel, based on the research grouping that employs them, under which the quality of their research will be reviewed but where the panel subjects are based on traditional areas of research interest. This addresses an on-going problem since multidisciplinary is already perceived as a disadvantage to performance in research evaluation
Rinia et al. (2001); Nightingale and Scott (2007). A number of studies have indicated that peer review is biased against multidisciplinary research Laudel and Origgi (2006); Langfeldt (2006), and therefore it is likely that ECR author credit, in this already complicated environment, requires a degree of protection. It is advisable that author inclusion and positioning on multidisciplinary research or interdisciplinary research publications is discussed and agreed on reasonably prior to project commencement or indeed completion. At ECR level, many individuals are at a transitional stage from self-focused small projects to larger scale research projects. An established multidisciplinary committee can help provide the support and training necessary for ECRs and since multidisciplinary research is both new and different from the majority of research, it is an area that needs particular support. Following skill enhancement, ECRs can use multidisciplinary research as a useful tool for research continuation and career progression.

\section{ECR Utilisation}

There are many opportunities for senior academics to pursue multidisciplinary activities, as there has been a longer period to build professional networks and impressive CVs that appeal to those trying to start new relationships. In addition to senior academics it is often found that post-graduate students are well represented within this community, largely due to the highly regulated governance of $\mathrm{PhD}$ studentships and efforts to ensure that they are well supported throughout their degree program. ECRs tend to fall into an unusual category since they are often working individually without the support of supervisors or a wide network of work colleagues. This can be further exacerbated by the fact that these individuals are often on short term, or fixed term contracts making it difficult to find and build relationships in these time frames. However, these are the same researchers who should be performing high quality research, are malleable in their thought process and are enthusiastic about new ideas. It is therefore logical that they are encouraged to pursue multidisciplinary activities for the benefit of their host institution, and themselves. 


\section{ECR Committee Sustainability}

In order to maintain an environment that is inclusive and supportive of ECRs in multidisciplinary, it was proposed to make the committee and its activities sustainable. It was anticipated that the committee to become a permanent feature of the University of Southamptons research environment and ECR placement within the USRGs to continue into the future. Transient ECR involvement would not provide optimal benefits and it was important to generate as much continuity between years as possible. Other problems faced were that ECRs are not obliged contractually, and in some cases are discouraged, from partaking in University activities. Therefore the committee would need to be as low maintenance as possible, while actively giving something back to those who chose to participate.

\subsection{Conference}

To introduce the ECR committee and to initiate the committee's objectives, a 2-day conference was held. The aim of the conference, the Southampton Multi-disciplinary Research Forum (SMuRF), was to promote and facilitate the involvement of ECRs in multidisciplinary and interdisciplinary research activity at the University of Southampton.

SMuRF was a dynamic and multifaceted event designed specifically to promote and raise awareness of multidisciplinary research, while providing a platform for ECRs to meet those in other fields. Seminars were held in order to inform the ECR community of the University's multidisciplinary strategy, and that of the research councils and other funding bodies, and explore opportunities. Information on how to attract and obtain funding was given, in addition to workshops intended to demonstrate how successful multidisciplinary funding bids are generated, and how peer review evaluates such bids. Speed networking events were included to provide a means for individual ECRs to develop a wider network inclusive of other ECRs from a range of scientific disciplines. Senior academics were also present to provide further networking opportunities and case study information. Workshops to encourage ideas between ECRs and to initiate relationships were a popular and successful component of the event. The conference was also designed to recruit ECRs as future committee and USRG members, and to inform the ECRs of the support and objectives of the SMuRF committee itself.

\section{Implementation}

The first action of the ECR committee focused on the development of the Southampton Multidisciplinary Research Forum (SMuRF). This was held in the De Vere Grand Harbour hotel in Southampton on the 16th and 17th of February 2012 (total duration of sixteen hours, plus the conference dinner). The conference was held off campus to avoid disruption and ensure attendees were focused on the conference.

\subsection{Learning Objectives}

The overall vision of the forum was to promote and facilitate the involvement of ECRs in multidisciplinary and interdisciplinary research activity at the University of Southampton. In order to achieve this, four learning objectives were set: stimulate; inform; train; and network. Each of the forum sessions was concerned typically with trying to fill as many of these objectives as possible. The learning objectives are described below.

\section{Stimulate}

The first step was to promote ECRs involvement in multidisciplinary research to stimulate their desire to engage in such activities. This objective was pursued with two actions: firstly, examples were presented to the attendees of successful Multidisciplinary research projects. These examples were presented by academic staff of the University of Southampton that are engaged in multidisciplinary research and the external key-note speaker. These lectures communicated the attractiveness of multidisciplinary research due to the intrinsic wide range of research 
topics involved and to the associated research challenges. The speakers also discussed the opportunities provided by multidisciplinary research, especially in terms impact of the research on the community and on their academic career. Some of the lectures explained the obstacles that arise when conducting multidisciplinary research, and discussed how these were overcome or in cases where they were not, where the lessons were learnt. Furthermore these lectures also formed a focus to help those who had not worked in multidisciplinary research to generate new ideas and understand the concept. Secondly the ECRs were informed of the importance of multidisciplinarity at a local (University of Southampton) and national level. The Pro Vice-Chancellor for research and the director of Multidisciplinary Research Strategy at the University of Southampton explained the relevance of multidisciplinary research to the University strategy. Delegates of two national research councils (Engineering and Physical Sciences Research Council (EPSRC) and Natural Environment Research Council (NERC)) discussed the role of multidisciplinary research in the national programmes.

\section{Inform}

The attendees were made aware of a variety of support structures and mechanisms that can support multidisciplinary research.

- The delegates of the national research councils provided an overview of the existing funding schemes to support research and of the available mechanisms to access these funds.

- The director of Multidisciplinary Research Strategy of the University of Southampton introduced the University Strategic Research Groups and discussed how these structures can be used by ECRs to support multidisciplinary research.

- The head of Faculty Support of the University's Research and Innovation services provided an overview of the intellectual property issues that might arise when undertaking multidisciplinary research and explained how ECRs can benefit from the support of the Research and In- novation Services to create and further new research collaborations.

- The head of the Professional Development Unit provided information on the concordat outlining the key skills for a developing researcher and providing information on the rights that ECRs have.

\section{Train}

Training sessions were provided to increase the skill sets of the participants. These included writing research grant applications, involving external collaborators and identifying the obstacles, opportunities and impact of multidisciplinary research.

\section{Network}

The forum represented an opportunity for ECRs to interact with colleagues from different faculties and to explore possibilities of collaborative research. In order to facilitate this process, a number of organized speed-networking sessions were undertaken, wherein the attending ECRs were asked to engage in individual discussions on their research with one colleague and for a limited amount of time, after which they were asked to change partner. At the end of this process, the attending ECRs had the opportunity to draft the outline of collaborative multidisciplinary research projects, which were submitted and evaluated by a panel of academics (during the forum). The project that was recognized by the panel as the most promising was awarded a prize by the Vice-Chancellor of the University of Southampton during the closing speech of the forum.

\subsection{Design of Forum Sessions}

The forum was organized in a number of sessions, whose different structures and associated activities can be categorized as follows:

1. Lectures. Given either by members of the academic staff of the University of Southampton, the Pro-Vice Chancellor for research or by invited external speakers. 
2. Surgeries. On specific problems and case studies, wherein groups of ECRs were asked to work under the guidance of one academic experienced in multidisciplinary and interdisciplinary research.

3. Collective sessions. The session coordinator addressed research-related issues and posed questions. The attendees were requested to reflec$\mathrm{t}$ upon and to answer. Feedback was collected with the aid of an Electronic Voting System (zappers) and the statistical data were displayed in real time and discussed.

4. Speed-Networking sessions. Wherein the attendees were asked to engage in individual conversations and to discuss their research activity and interests.

The aim of the programme was to follow the process of multidisciplinary research from cradle to grave with sessions on each section from writing a research grant, gathering a team, running the grant and then how to make the most of these research areas. This was augmented by discussions on opportunities and importance of multidisciplinary research. A detailed programme of the conference can be found in table 2 .

[Table 3 about here.]

\subsection{Forum Appraisal}

The Southampton Multidisciplinary Research Forum (SMuRF) aimed to promote and facilitate the involvement of ECRs in Multidisciplinary and interdisciplinary research activity at the University of Southampton. As a means to provide quantitative and qualitative measurement, pre- and post- event questionnaires were completed by the attendees. These provided an indication of interest (size and discipline), ECRs attitudes (pre- and post- event) and whether an event and/or committee provides tangible improvements in multidisciplinary awareness or changed perceptions. The results and a discussion of the results of these questionnaires are presented in section 4 .

\subsection{Forum Budget}

The estimated budget for the conference was $£ 12,000$. A breakdown of expenses is outlined in table 3 .

\section{[Table 4 about here.]}

While this budget was large it was felt that the numbers of ECRs that it reached were high. The final total per attendee was $£ 135.92$ for two days training and provided added benefits such as networking between a large number of participants and the capability to run these sessions for a large group of people. Furthermore the size of the event allowed a larger number of higher profile speakers to be invited, broadening the perspective of those involved. A larger budget was used as this was the first event and therefore its success was important to generate initial ECR response.

\section{Results and Discussion}

A total of 76 attended, the majority of which held a research fellow position, while estimates at the University of Southampton vary for the number of ECRs it is assumed that this figure is around 1000 and therefore $7.6 \%$ of the target audience was achieved. Attendees from seven of the eight faculties of the University. In order to gauge a priori knowledge and relevance, the delegates were asked to complete two questionnaires; one pre- and one post-conference.

The pre-questionnaire was distributed to all delegates upon registration and collected before the lunchtime session on the first day. The prequestionnaire was comprised of six statements, ranked with a five-point visual-analogue scale ( $5=$ strongly agree, $1=$ strongly disagree). The following statements were included:

1. Multidisciplinary research is highly important to my future 
2. I feel confident working in multidisciplinary research

3. I have a strong research network outside of my area of expertise

4. I have an excellent knowledge of the research council's policies and calls relating to multidisciplinary research

5. I currently work closely with external industrial collaborators

6. I have an excellent understanding of the research strategy of the University of Southampton

Seven out of the eight Faculties were captured in both the pre- and post-conference questionnaires, figure 1. In both cases, only the Faculty of Humanities was absent. The abbreviations for the other Faculties can be found in the nomenclature:

[Figure 1 about here.]

Of the sample, 53 delegates returned the prequestionnaire (one delegate did not rank statement 4). Figure 2 illustrates the pre-conference results:

[Figure 2 about here.]

In contrast, the post-conference questionnaire was distributed after lunch on the second day of the conference. Delegates were asked to rank eleven statements using the same five-point scale. The following statements were included:

\footnotetext{
${ }^{0}$ For the sake of clarity the statements 1 and 2 have been merged into a single one "Disagree", while 4 and 5 were also combined "Agree"
}

1. I have gained a better awareness of the importance of multidisciplinary research and of its potential on my career in research

2. What I have learned will prove useful when writing future grant applications

3. This event helped me strengthen/broaden my network of professional contacts within the University

4. This event has helped/will help me create new multidisciplinary research collaborations

5. I plan to write a multidisciplinary research grant with someone I met at the event

6. I am more likely to work with external industrial collaborators in the future

7. I have gained a better knowledge of the UK research funding bodies and of their policies

8. I have gained a better understanding of the research strategies of the University of Southampton

9. Overall rating of the event (five point scale altered to $5=$ very good to $1=$ very poor)

10. The event addressed my needs

11. Would you recommend this event to a colleague/fellow student?

In total, 35 delegates completed the postconference questionnaire (one delegate did not rank statement 7 ). Figure 3 illustrates the results. 
[Figure 3 about here.]

The results show that the breakdown of ECRs between faculties was fairly evenly split where the rate was slightly higher among those subjects with a maths and science bias and attendance being particularly low in the Faculty of Humanities and Faculty of Natural and Environmental Sciences. It can be seen from the results of the questionnaire that before the conference started many of the researchers felt that multidisciplinary research was important to their future. The event was developed to help those interested in multidisciplinary research and therefore there will be a bias from this group towards an appreciation for multidisciplinary research. However, it is an indicator of the growing importance or perceived value of multidisciplinary research. Furthermore, many of the researchers felt that they were confident working in multidisciplinary research. This result goes against the perception that multidisciplinary research is more difficult to break into. This result might have been generated as the researchers working in this area were more experienced in this area and attended the conference based on this. Conversely there is also the possibility that researchers had not performed truly multidisciplinary research and did not see the possible complexities to this type of research. However, even though the results show that multidisciplinary research was important and that ECRs were confident in working in this manner, it was generally felt that most of the ECRs did not have a strong network outside of their area of expertise or that they had close external collaborations.

Finally the researchers felt that they lacked knowledge of the Research Councils and had a relatively poor understanding of the internal research strategy. These last four results would seem to be contradictory to the result that ECRs felt confident working in multidisciplinary research. This is an area of interest and more research should be performed in this area. Furthermore these results show that there is an interest in multidisciplinary research and that ECRs are comfortable in performing this research but they lack an understanding of the contacts and horizon searching that is vital for internationally significant research. This indicates that the support required for ECRs is most needed in the areas of improving contacts and increasing knowledge of multidisciplinary strategy, both internally and externally.

The post event replies from the researchers were different, reflecting the knowledge gained from interaction with other researchers and with expert speakers on various topics. The results show that the conference improved the awareness of the importance of multidisciplinary research, although this was against a background of researchers who already felt that multidisciplinary research was important. Furthermore the forum was also useful for improving research grant applications. Whilst at the beginning of the conference the ECRs felt that they had poor networks it was felt that these had been broadened as the ability to network during the conference, both formally and informally, allowed these networks to grow. By the end of the forum, a number of the participants felt that they had found people to collaborate with and some even may go on to write a new research grant. The ability to find new networks and to develop new research grants was actively encouraged during the conference with competitions aimed at developing links between researchers; specifically writing research grants between the forum attendees. The conference was also helpful in expanding the knowledge of the UK Research Councils and informing the participants of the research strategies within the University.

Whilst the conference focused on multidisciplinary research, it can be seen from the results that there were other benefits associated with running a university-wide conference. It was interesting to note that before the conference, the ECRs reported that they were capable of performing multidisciplinary research but that there networks of researchers in other fields were poor. The most important parts of the conference were that they allowed members of the University to meet those in other groups but also allowed ECRs, who can often be a transient population, to quickly assimilate themselves into the Universities multidisciplinary strategy. Whilst there are other formats that may benefit the integration and training of ECRs, it was felt that this method- 
ology allowed a good compromise between the two goals, while also promoting to the ECRs that they are involved in the development of the university's multidisciplinary strategy.

Whilst there were many benefits to the use of a conference in expanding the role of ECRs into multidisciplinary research there were some disadvantages in the use of this method. The conference was work intensive for the members of the organising committee involving a large amount of hours oreganising the workshops and attendees. Since the conference was for ECRs it was also organised for ECRs and therefore time spent on this activity is not recognised in the metrics for rewarding at this level. To increase the sustainability of the committee it has been decided to reduce the workload of the committee members. For future versions of the committee the aim will be for the ECRs to generate ideas and find out the opinions of the ECR body but to avoid large amounts of organisational work. This will result in the activities from the conference being spread throughout the year. Whilst this may result in the loss of some of the prestige associated with this event, it is hoped that this can still provide the training and networking it was felt was most required from the ECRs.

\section{Conclusions}

Currently it is felt that ECRs are an underused resource within multidisciplinary research as most networking opportunities are found at higher levels. Added to this, it can be hard to develop research that may not be accounted for in standard academic metrics. For universities to implement this type of research into their strategies it will be imperative to support, train and develop ECRs. The University of Southampton are developing a university-wide University Strategic Research Group and there is a desire to incorporate ECRs needs into their new policy. A committee has therefore been setup and as part of this drive a conference, SMuRF, has been launched as a method of incorporating
ECRs into multidisciplinary research and to help further training. This paper investigates the use of a conference as a method of integrating ECRs into multidisciplinary research and discusses findings about the requirements of ECRs in the area of multidisciplinary research. It was found that ECRs are comfortable in performing multidisciplinary research but feel they lack knowledge about internal and external strategies making it difficult to form long term views and also developing their networks in other disciplines. The conference was successful in increasing the knowledge of ECRs on the topic of multidisciplinary research targeting increased knowledge of a range of topics and to generate new collaborations across the different faculties at the University of Southampton. This format was useful for providing the ECRs training, a place to network and provided a method by which the ECRs felt included within the University of Southampton's Multidisciplinary research strategy. It is also helped that incorporating more ECRs and expanding their skill sets leads to easier retention of ECRs in the future. The outcome of this is that ECRs have the capabilities required to effectively push multidisciplinary research forward but need to have opportunities. An initiative such as the one described here provides such opportunities.

\section{Acknowledgments}

The Southampton Multidisciplinary Research Forum (SMuRF) was supported by the Roberts' Fund.

\section{References}

Attard, G., Nelson, P., 2010. Strategy for Multidisciplinary Research. Technical Report. University of Southampton.

Bozeman, B., Corley, E., 2004. Scientisits collaboration strategies: implications for scientific and technical human capital. Research Policy 33, 599-616.

Choi, B., Pak, A., 2006. Multidisciplinarity, in- 
terdisciplinarity and transdisciplinarity in health research, services, education and policy: 1. definitions, objectives and evidence of effectiveness. Clinical and Investigative Medicine 29, 351-364.

Gibbons, M., Scott, P., Nowotny, H., Limoges, C., Trow, M., Schwartzman, S., 1994. The New Production of Knowledge: the dynamics of science and research in contemporary societies. London: SAGE.

Hessels, L., 2010. Science and the struggle for relevance. Ph.D. thesis. University of Utrecht.

Hollingsworth, R., Hollingsworth, E., 2000. Radikale innovationen und forschungsorganisation: Eine annaherung. Osterreichische Zeitschrift fur Geschichtswissenschaften 115, 31-66.

Jacobs, J.A., Frickel, S., 2009. Interdisciplinarity: a critical assessment. Annual Review of Sociology $35,43-65$.

Langfeldt, L., 2006. The policy challenges of peer review: managing bias, conflict of interests and interdisciplinary assessments. Research Evaluation $15,31-41$.

Laudel, G., Origgi, G., 2006. Special issue on the assessment of interdisciplinary research. Research Evaluations 15, 2-4.

Lowe, P., Phillipson, J., 2006. Reflexive interdisciplinary research: The making of a research programme on the rural economy and land use. Journal of Agricultural Economics 57, 165-184.

Nightingale, P., Scott, A., 2007. Peer review and the relevance gap: ten suggestions for policy-makers. Science and Public Policy 34, 543553.

Reeves, J., Denicola, P., Metcalfe, J., Roberts, J., 2012. The Vitae Researcher Development Framework and Researcher Development Statement: methodology and validation report. Technical Report. Vitae.

Rhoten, D., Pfirman, S., 2007. Women in interdisciplinary science: exploring preferences and consequences. Research Policy 36, 56-75.
Rijnsoever, F., Hessels, L., 2011. Factors associated with disciplinary and interdisciplinary research collaboration. Research Policy 40, 463-472.

Rinia, E., van Leeuwen, T., van Vuren, H., van Raan, A., 2001. Influence of interdisciplinarity on peerreview and bibliometric evaluations in physics research. Research Policy 30, 357-361. 

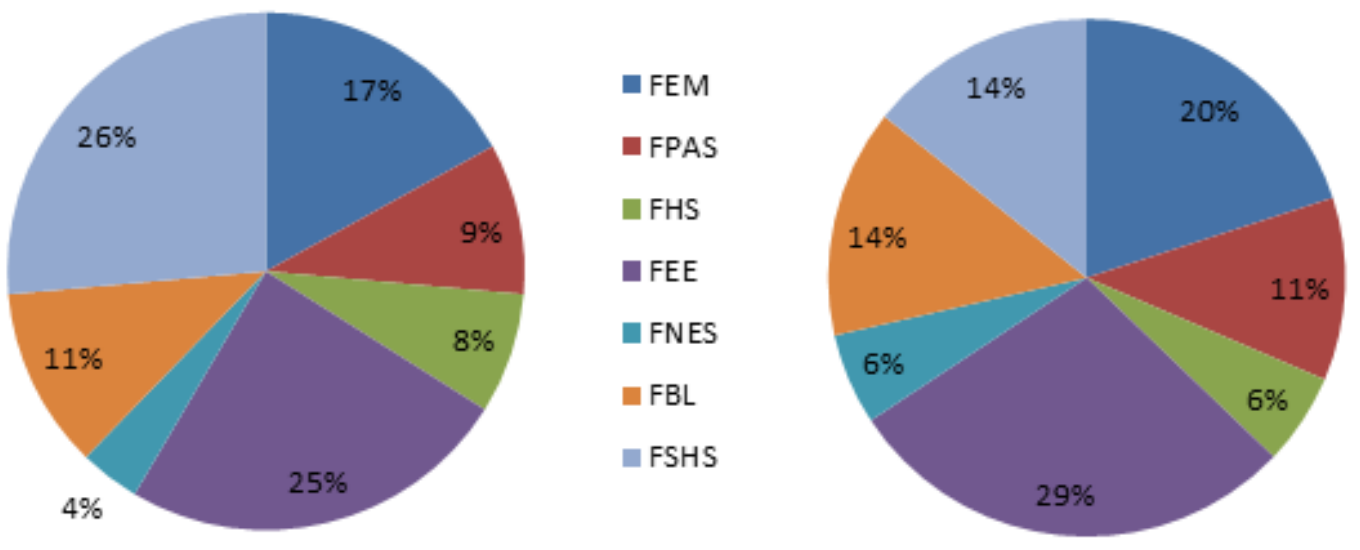

Figure 1: Break down of replies to questionnaire Left: Pre-conference Right: Post-Conference 


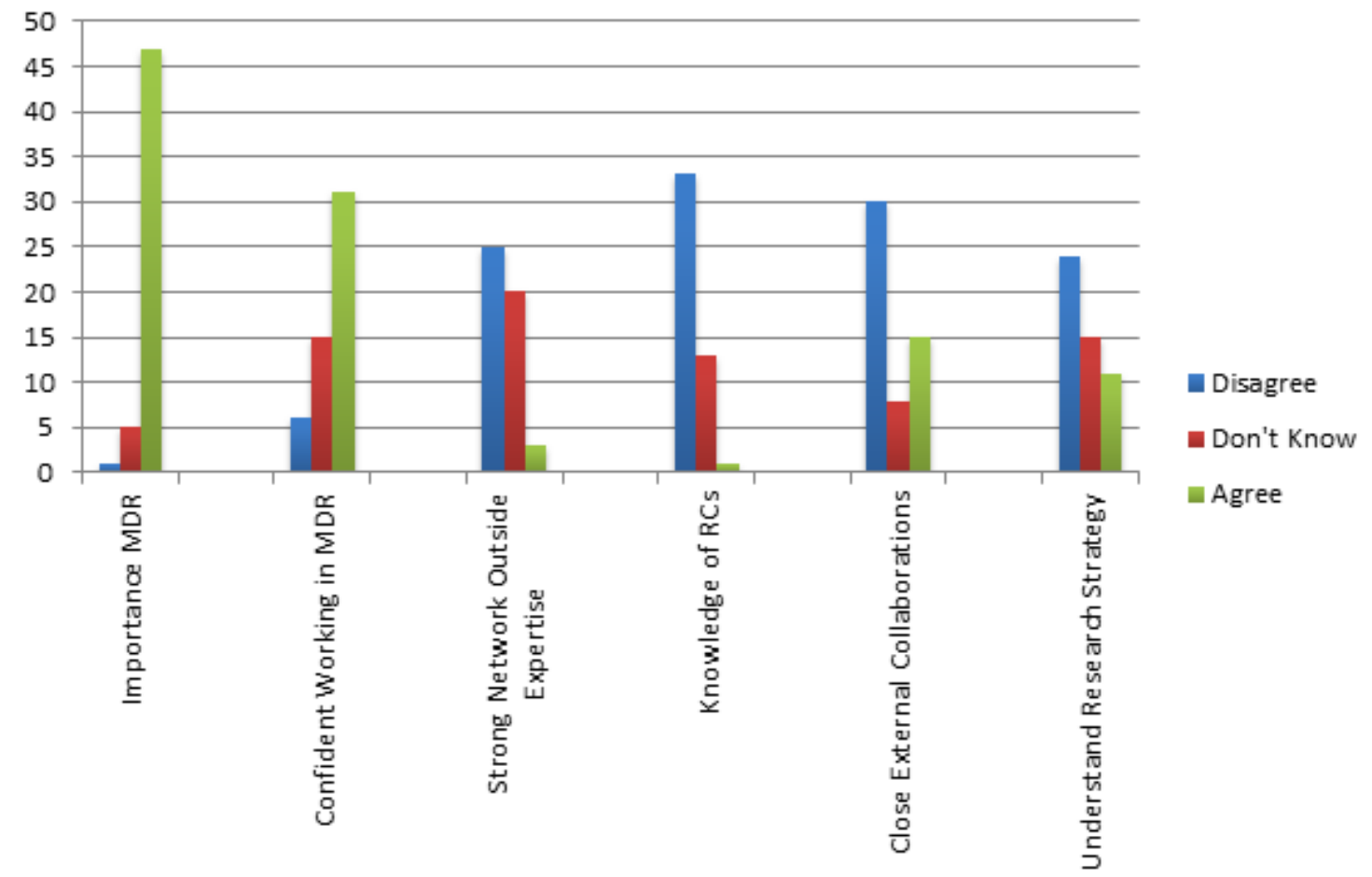

Figure 2: Pre-conference questionnaire results ${ }^{1}$ 


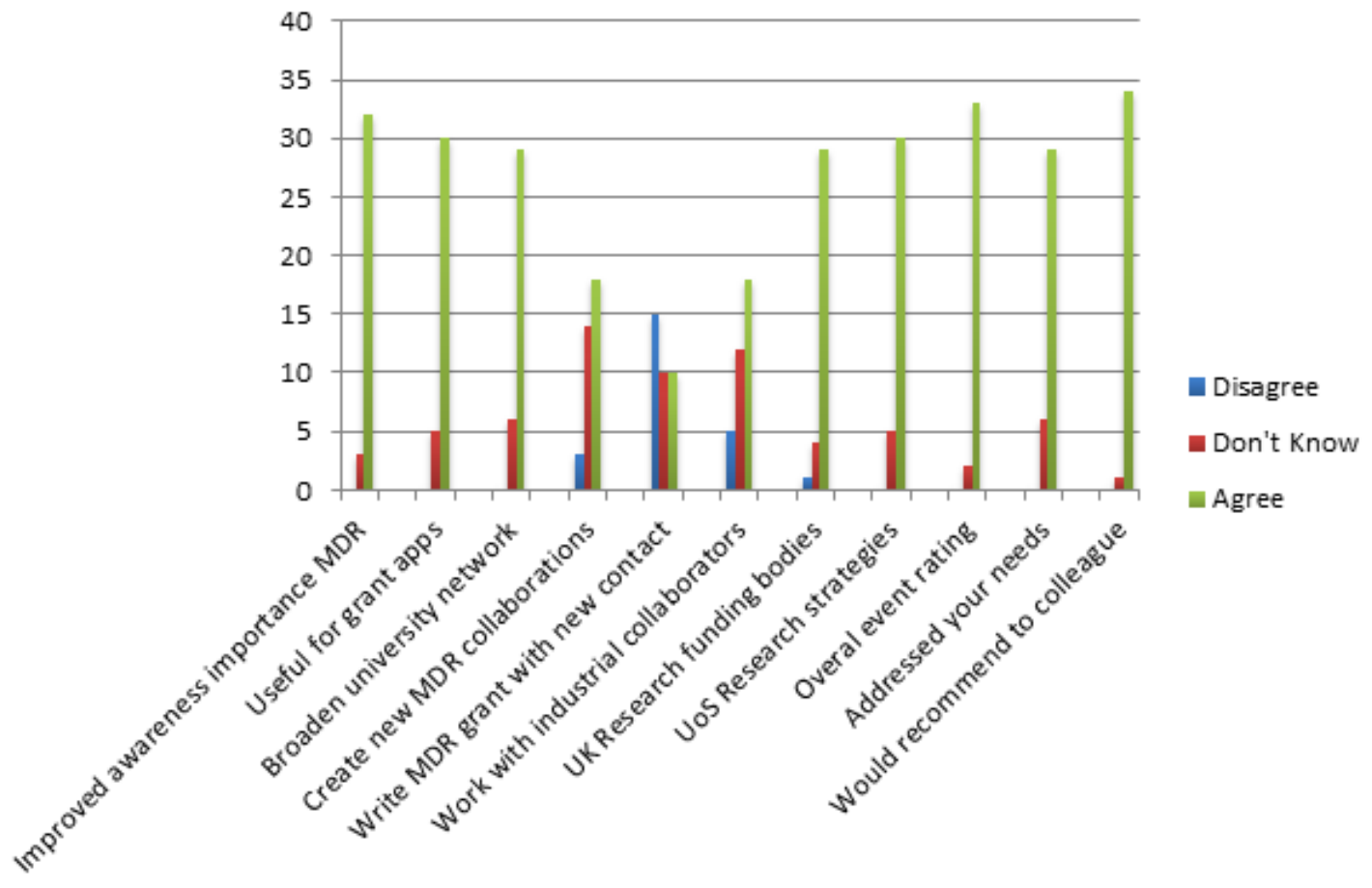

Figure 3: Post-conference questionnaire results ${ }^{1}$ 


$\begin{array}{ll}\text { ECR } & \text { Early Career Researcher } \\ \text { EPSRC } & \text { Engineering and Physical Sciences Research Council } \\ \text { FBL } & \text { Faculty of Business and Law } \\ \text { FEE } & \text { Faculty of Engineering and the Environment } \\ \text { FEM } & \text { Faculty of Medicine } \\ \text { FH } & \text { Faculty of Humanities } \\ \text { FHS } & \text { Faculty of Health Sciences } \\ \text { FNES } & \text { Faculty of Natural and Environmental Sciences } \\ \text { FPAS } & \text { Faculty of Physical and Applied Sciences } \\ \text { FSHS } & \text { Faculty of Social and Human Sciences } \\ \text { NERC } & \text { Natural Environment Research Council } \\ \text { SMuRF } & \text { Southampton Multidisciplinary Research Forum } \\ \text { USRG } & \text { University Strategic Research Group }\end{array}$




\begin{tabular}{|c|c|c|c|c|c|c|c|c|c|}
\hline USRG Faculty Distribu- & \multicolumn{9}{|c|}{$\overline{\text { University Faculties }}$} \\
\hline $\begin{array}{l}\text { University Research Stategic } \\
\text { Groups (USRGs) }\end{array}$ & $\begin{array}{l}\text { Business } \\
\text { and Law }\end{array}$ & $\begin{array}{l}\text { Engineering } \\
\text { the Envi- } \\
\text { ronment }\end{array}$ & $\begin{array}{l}\text { Health Sci- } \\
\text { ences }\end{array}$ & Humanities & Medicine & $\begin{array}{l}\text { Natural } \\
\text { and Envi- } \\
\text { ronmental } \\
\text { Sciences }\end{array}$ & $\begin{array}{l}\text { Physical } \\
\text { and Ap- } \\
\text { plied } \\
\text { Sciences }\end{array}$ & $\begin{array}{l}\text { Social and } \\
\text { Human Sci- } \\
\text { ences }\end{array}$ & Other \\
\hline Ageing and Lifelong health & $4.84 \%$ & $8.06 \%$ & $1.61 \%$ & $1.61 \%$ & $12.90 \%$ & $8.06 \%$ & $0.00 \%$ & $3.00 \%$ & $14.52 \%$ \\
\hline $\begin{array}{l}\text { Complexity in Real World } \\
\text { Context }\end{array}$ & $2.16 \%$ & $25.90 \%$ & $0.00 \%$ & $2.16 \%$ & $3.24 \%$ & $18.71 \%$ & $21.58 \%$ & $17.63 \%$ & $8.63 \%$ \\
\hline $\begin{array}{l}\text { Computationally Intensive } \\
\text { Imaging }\end{array}$ & $3.57 \%$ & $26.19 \%$ & $3.57 \%$ & $4.76 \%$ & $10.71 \%$ & $10.71 \%$ & $13.10 \%$ & $10.71 \%$ & $16.67 \%$ \\
\hline Digital Economy & $14.29 \%$ & $9.77 \%$ & $3.01 \%$ & $2.26 \%$ & $2.26 \%$ & $4.51 \%$ & $43.61 \%$ & $12.03 \%$ & $8.27 \%$ \\
\hline Energy & $1.49 \%$ & $38.81 \%$ & $0.00 \%$ & $0.00 \%$ & $0.00 \%$ & $10.45 \%$ & $7.46 \%$ & $23.88 \%$ & $17.91 \%$ \\
\hline Health Technologies & $7.28 \%$ & $10.60 \%$ & $15.89 \%$ & $1.32 \%$ & $23.84 \%$ & $2.65 \%$ & $8.61 \%$ & $13.25 \%$ & $16.56 \%$ \\
\hline Institute for Life Sciences & $0.94 \%$ & $8.45 \%$ & $3.29 \%$ & $0.94 \%$ & $29.58 \%$ & $24.88 \%$ & $8.45 \%$ & $6.57 \%$ & $16.90 \%$ \\
\hline Nanoscience & $0.91 \%$ & $12.73 \%$ & $0.00 \%$ & $0.00 \%$ & $24.55 \%$ & $18.18 \%$ & $31.82 \%$ & $4.55 \%$ & $7.27 \%$ \\
\hline Neurosciences & $0.00 \%$ & $1.85 \%$ & $11.11 \%$ & $1.85 \%$ & $33.33 \%$ & $16.67 \%$ & $0.00 \%$ & $24.07 \%$ & $11.11 \%$ \\
\hline Population Health & $0.56 \%$ & $6.74 \%$ & $7.87 \%$ & $0.56 \%$ & $31.46 \%$ & $1.12 \%$ & $1.69 \%$ & $19.10 \%$ & $30.90 \%$ \\
\hline $\begin{array}{l}\text { Southampton Marine and } \\
\text { Maritime Institute }\end{array}$ & $11.07 \%$ & $27.67 \%$ & $0.40 \%$ & $8.70 \%$ & $0.00 \%$ & $33.99 \%$ & $2.77 \%$ & $10.67 \%$ & $4.74 \%$ \\
\hline $\begin{array}{l}\text { Sustainability Science at } \\
\text { Southampton }\end{array}$ & $7.69 \%$ & $12.39 \%$ & $1.28 \%$ & $2.14 \%$ & $3.42 \%$ & $13.25 \%$ & $13.25 \%$ & $28.21 \%$ & $18.38 \%$ \\
\hline $\begin{array}{l}\text { Work Futures Research cen- } \\
\text { tre }\end{array}$ & $14.86 \%$ & $1.35 \%$ & $9.46 \%$ & $4.05 \%$ & $4.05 \%$ & $0.00 \%$ & $2.70 \%$ & $51.35 \%$ & $12.16 \%$ \\
\hline
\end{tabular}

Table 1: Faculty distribution of the University Strategic Research Groups at the University of Southampton 


\begin{tabular}{|c|c|c|c|c|}
\hline Event & Stimulate & Inform & Train & Network \\
\hline \multicolumn{5}{|l|}{ Day 1} \\
\hline Sources of funding for multidisciplinary research & $\mathrm{x}$ & $\mathrm{x}$ & & \\
\hline Speed networking & $\mathrm{x}$ & & & $\mathrm{x}$ \\
\hline External Keynote Speech & $\mathrm{x}$ & & & $\mathrm{x}$ \\
\hline Writing multidisciplinary grant applications & & $\mathrm{x}$ & $\mathrm{x}$ & $\mathrm{x}$ \\
\hline Speed networking & $\mathrm{x}$ & & & $\mathrm{x}$ \\
\hline Multidisciplinary research case studies & $\mathrm{x}$ & $\mathrm{x}$ & & \\
\hline Conference dinner & & & & $\mathrm{x}$ \\
\hline \multicolumn{5}{|l|}{ Day 2} \\
\hline Involving external collaborators & $\mathrm{x}$ & $\mathrm{x}$ & $\mathrm{x}$ & $\mathrm{x}$ \\
\hline Obstacles in conducting multidisciplinary research & & $\mathrm{x}$ & $\mathrm{x}$ & \\
\hline Internal Keynote Speech & $\mathrm{x}$ & $\mathrm{x}$ & $\mathrm{x}$ & \\
\hline Opportunities of multidisciplinary research & $\mathrm{x}$ & $\mathrm{x}$ & $\mathrm{x}$ & $\mathrm{x}$ \\
\hline University Strategic Research Groups Perspective & $\mathrm{x}$ & $\mathrm{x}$ & $\mathrm{x}$ & \\
\hline Impact of multidisciplinary research & $\mathrm{x}$ & $\mathrm{x}$ & $\mathrm{x}$ & $\mathrm{x}$ \\
\hline Closing address by the Vice Chancellor & $\mathrm{x}$ & & & \\
\hline
\end{tabular}

Table 2: Programme of ECR Conference 


\begin{tabular}{lc} 
Activity & Cost $(£)$ \\
\hline \hline Venue & 7,346 \\
\hline Dinner & 2,250 \\
\hline Miscellaneous & $1,311.31$ \\
\hline Total & $10,907.31$ \\
\hline \hline
\end{tabular}

Table 3: Budget of ECR Conference 